\title{
EXAMINING THE USER EXPERIENCE OF LIFE CYCLE ASSESSMENT TOOLS AND THEIR ABILITY TO CATER TO ECODESIGN IN EARLY-STAGE PRODUCT DEVELOPMENT PRACTICE
}

\author{
Chatty, Tejaswini; \\ Qu, Yingkun; \\ Ba-Sabaa, Hana H.; \\ Murnane, Elizabeth L. \\ Dartmouth College
}

\begin{abstract}
With the topic of sustainability steadily gaining importance and public awareness, there is growing consensus about the need to incorporate environmental considerations in early stage product development (PD). This makes it imperative for PD practitioners to have access to methods and tools, including life cycle assessment (LCA), that support sustainability integration. This paper evaluates existing LCA tools on their ability to cater to the early-stage PD context, by having users apply the tools in practice and exploring their experiences. We find that the challenges to applying LCA in this context emanate primarily from the shortcomings of the tools themselves. Our evaluation metrics for tool critique are derived from a thematic analysis of user interviews we conducted, refined according to information and interaction design principles from human-computer interaction (HCI). This unique approach helps triangulate insights from users with literature, to produce design recommendations for the development of novel LCA tools tailored to the early PD context.
\end{abstract}

Keywords: Life Cycle Assessment, Ecodesign, Integrated product development, Sustainability

\author{
Contact: \\ Chatty, Tejaswini \\ Dartmouth College \\ Thayer School of Engineering \\ United States of America \\ Tejaswini.Chatty.TH@dartmouth.edu
}

Cite this article: Chatty, T., Qu, Y., Ba-Sabaa, H. H., Murnane, E. L. (2021) 'Examining the User Experience of Life Cycle Assessment Tools and Their Ability to Cater to Ecodesign in Early-Stage Product Development Practice', in Proceedings of the International Conference on Engineering Design (ICED21), Gothenburg, Sweden, 16-20 August 2021. DOI:10.1017/pds.2021.405 


\section{INTRODUCTION}

Ecodesign integrates sustainability considerations into product development (PD) to help minimize environmental impacts (Johansson, 2002). Given most impacts are defined in the early stages of PD (Devanathan et al., 2010), consensus has grown around the need to consider sustainability at this "fuzzy front-end" (Chiu and Chu, 2012). These early phases are often rife with uncertainties as critical decisions like choice of material, manufacturing processes, product architecture, and distribution methods are yet to be made. Bhander et al., (2003) termed this the "ecodesign paradox", where designers have the freedom to make changes early-on but are impeded by the uncertainties.

The sustainable design community's strategies range from qualitative checklists to quantitative impact assessment methods (Bocken et al., 2012). We focus on life cycle assessment (LCA), a quantitative method to evaluate the environmental impacts throughout a product's life cycle, encompassing extraction of raw materials, manufacturing, distribution, use, and disposal. Some argue LCA is the most powerful method to evaluate environmental performance in PD (Januschkowetz and Hendrickson, 2001). While there are challenges to using LCA in preliminary design phases (Bhander et al., 2003; Millet et al., 2007), this early application is advantageous, as it enables designers and engineers to measure, identify, and compare environmental impacts across product concepts and thereby supports data-driven ecodesign decisions. In this paper, we evaluate existing LCA tools on their ability to cater to early-stage PD. Through interviews with practitioners, we investigate tools' strengths and weaknesses and formulate a rubric to rate them on user-centered criteria. Based on these insights, we make design recommendations for tailoring future LCA tools to early PD contexts.

\section{LITERATURE REVIEW}

\subsection{Life Cycle Assessment (LCA) processes and phases}

LCA examines the potential environmental impacts throughout a product's life cycle via four distinct phases, per ISO 14040 \& 14044 (ISO, 2006): Goal and Scope Definition establishes the goals of the assessment, functional unit, system boundaries, and data granularity. Life Cycle Inventory (LCI) quantifies energy requirements, raw material needs, and emissions. Life Cycle Impact Assessment (LCIA) evaluates the magnitude and significance of a product's potential environmental impacts. Finally, Interpretation identifies hotspots based on LCIA results; evaluates completeness, sensitivity, and consistency; and documents conclusions, limitations, and recommendations (Curran, 2016). LCA has traditionally been employed as a static retrospective analysis (da Luz et al., 2018) to report impacts as environmental product declarations (EPDs), rather than to support early stage ecodesign.

\subsection{LCA in early-stage product development}

Product development (PD) comprises a "set of activities beginning with the perception of a market opportunity and ending in the production, sale, and delivery of a product" (Ulrich and Eppinger, 2020). The fuzzy front-end (FFE) of PD includes activities such as opportunity identification, market analysis, and product definition (Khurana and Rosenthal, 1998), which do not occur in a linear fashion. The main objective of incorporating LCA in PD is to help decision makers choose design alternatives with better environmental performance (Agustí-Juan and Habert, 2017). Several studies have looked at applying LCA in PD such as predicting impacts of design alternatives (Kuo et al. 2016), sustainable production (Lacasa et al., 2016), and sustainable innovation (Russo et al., 2014).

The earlier in the PD process that LCA is incorporated, the greater the potential for impact (Depping et al., 2017). However, Bhander et al., (2003) identified factors that challenge this early application. First, performing an LCA requires extensive data on material, process, and energy that may not yet be defined in the early stages. Obtaining this data and building a model can be time-consuming, especially if there is uncertainty. LCA is also often a static retrospective analysis, yet PD environments are dynamic and iterative. Lastly, performing an LCA and translating results into actionable decisions may require LCA expertise. Unfortunately, current tools are not designed to accommodate such constraints.

\subsection{LCA tools and human-centered design}

LCAs are typically performed using software that lets users input product data, choice of inventory databases, and impact assessment methodologies in order to compute environmental impacts (Baumann et al., 2002). The tools evaluated in our study range in complexity from those that support performing peer reviewed LCAs, to simplified LCA tools that are less rigorous and intended for 
internal decision making. These "screening-LCA" or "simplified-LCA" (SLCA) tools hasten the assessment process and ease adoption in contexts such as new product development (Lockrey, 2015) where decisions need to be made quickly. Specifically, SLCA tools are intended to enable quick improvement of the eco-efficiency of products and achieve a higher level of sustainable innovation, given a full scale LCA study is usually very detailed, expensive, and time-consuming to perform in the early stages of PD (Suppipat et al., 2021). Such tools have therefore been recommended for use in early-stage contexts, as they can provide systemic viewpoints despite limited quantitative data, while avoiding the complexity and time costs of a full-scale LCA (Pigosso and Sousa, 2011). Three out of five tools evaluated in this paper can be classified as simplified LCA tools.

Research on LCA software development has looked at integrating LCA with CAD software (Tao and Yu 2018), impact discrepancies across tools (Herrmann and Moltesen, 2015), localized LCA databases (Gong et al., 2006), and the expansion of LCIA capabilities (Rattanatum et al. 2018). At the intersection of LCA and PD, studies have explored integrating detailed and simplified LCA software into design processes (Casamayor and Su 2012) and examined that integration (Chang et al., 2014). Our paper offers design recommendations to guide the development of novel LCA tools tailored to early-stage PD. Our metrics are derived from a thematic analysis of interviews as well as established usability guidelines (Nielsen, 2012). We assess tools on learnability (Grossman et al., 2009), ease-of-use (Bevan et al., 2015), and effectiveness of visualizations (Wilke, 2019), together with other LCA-specific criteria.

\section{METHODOLOGY}

\subsection{Study site and participants}

Our research involved working closely with an engineering PD consultancy firm seeking to incorporate sustainability considerations into their design practices. Specifically, the first author worked as a sustainable design intern on a team of four engineers over four months, observing and participating in the PD process to discover how to integrate sustainable design and LCA. Participants P1, P2, and P3 were employees at the firm, who introduced us to P4, an LCA instructor, who we included in the study sample to broaden our scope of perspectives. P1 has a bachelor's degree and a master's degree in mechanical engineering, and over 8 years of work experience as a practicing engineer. P1 was in-charge of the sustainable design initiative at the company and learnt to use the advanced tools: SimaPro and Gabi. P2 and P3 have bachelor's degrees in mechanical engineering and close to 5 years of work experience. They used Sustainable Minds and Ecolizer respectively. P4 has over 10 years of experience teaching LCA using EarthSmart and shared insights on her students' experiences who were novice users of the tool.

Incorporating sustainability considerations into their workflow involved applying iterative cycles of 1) measuring environmental impacts using LCA, 2) identifying hotspots, 3) applying relevant design strategies to tackle those hotspots, in parallel with the PD processes (Chatty, 2020). Specifically, we tasked participants with using different LCA tools for a period of four months, as part of their typical design practices, with the goal of measuring the impacts of their concepts. We explored prominent LCA tools in the market ranging from industry-standard options for LCA experts (GaBi and SimaPro) to lightweight options that target novice users (EarthSmart, Sustainable Minds, and Ecolizer).

\subsection{Data collection}

Becoming embedded into the firm and working alongside our participants as an intern, the first author built a strong rapport and trust that promoted honest feedback during our in-depth semi-structured interviews. Each interview lasted an average of 45 minutes and followed the guide below.

\section{Learning curve:}

- How did you learn to use this tool, and how long did it take you to learn to use it?

\section{Tool walk-through:}

- Reflect on the activities performed, what you thought, and what you felt at each step?

Pause at the end of key sections (model setup, model-making, etc.) to discuss:

- How confident did you feel about the activities performed in this section?

- What interactions did you find satisfying/frustrating in this section?

Visualizations-specific questions:

- Does the format of the visualization support sensemaking? And communication?

- What are some features you like/dislike in the results section? 


\section{Reliability and coverage:}

- How would you rate the reliability of results obtained from this tool? Why?

- Address uncertainty in the results caused by: a) lack of precise data in the early stages; b) errors caused by tool complexity; c) underlying uncertainties in the LCI databases.

- How would you rate the breadth and depth of the database options available on this tool?

\subsection{Qualitative analysis}

To identify qualitative patterns in the interview data, we performed a thematic analysis that involved transcription, finding patterns, and generating codes (Braun and Clarke, 2006). We first agreed on toplevel themes, and then developed sub-themes through independent and collaborative iterations. Table 1 outlines the main themes and codes generated through an inductive approach.

Table 1. Coding scheme from thematic analysis of interviews with LCA tool users

\begin{tabular}{|c|c|}
\hline Main themes & Sub-theme (Description of the code) \\
\hline \multirow{3}{*}{ Learning curve } & Tool's guidance (e.g., pop-up instructions, video tutorials, expert help) \\
\hline & Necessity of prior experience (e.g., expertise with LCA concepts or other tools) \\
\hline & Time and effort it takes to learn \\
\hline \multirow{7}{*}{$\begin{array}{l}\text { Ease of use } \\
\text { (efficiency, } \\
\text { effectiveness, } \\
\text { satisfaction) }\end{array}$} & Efficient interaction with pages (slow load time, saving after every input, etc.) \\
\hline & Minimal number of clicks/steps to perform a task \\
\hline & Consistency in terminology \\
\hline & Redundancy in features \\
\hline & Supporting collaboration \\
\hline & Aesthetics of the tool \\
\hline & Familiarity based on prior experience with other tools (Excel, CAD tools, etc.) \\
\hline \multirow{3}{*}{$\begin{array}{l}\text { Breadth \& depth } \\
\text { of databases }\end{array}$} & Choice of inventory databases (e.g., ecoinvent) \\
\hline & Choice of impact assessment methods (e.g., TRACI, ReCiPe scoring, etc.) \\
\hline & Disposal scenarios (end-of-life) \\
\hline \multirow{3}{*}{ Uncertainty } & Uncertainty from tool complexity and novice confusion (lack of confidence) \\
\hline & Uncertainty in the database (unknown uncertainties in inventory databases) \\
\hline & Uncertainty in input information (limited knowledge in early stages of PD) \\
\hline \multirow{6}{*}{ Visualization } & Visualizations that support comparisons \\
\hline & Visualization format and aesthetic (for e.g., legends, labels and graph colors) \\
\hline & Representing uncertainty (error bars, blur charts, etc.) \\
\hline & Communication \& interpretation with colleagues (internally) \\
\hline & Communication with clients (externally) \\
\hline & Data exporting/visual summaries \\
\hline \multirow{3}{*}{ Standalone } & Using other tools to generate visualizations, write reports, etc. \\
\hline & Using other LCA tools to validate results \\
\hline & Using Excel to create a BOM for the product before data input \\
\hline \multirow{4}{*}{ Workflow } & Model setup: setting specs for analysis (functional unit, scope, etc.) \\
\hline & Model-making process \\
\hline & Analysis / calculations \\
\hline & Interpretation of results \\
\hline
\end{tabular}




\section{FINDINGS}

\subsection{Thematic analysis}

\subsubsection{Learnability and ease-of-use}

A key observation from our participation in the firm's workflow was that the engineers were highly constrained on time. Hence, for LCA to be adopted, it would have to be performed rapidly. Our interviews identified that a tool's swift learnability and efficient ease of use were therefore paramount. About her first modeling experience, $\mathrm{P} 2$ said, "If I really concentrated on it, it could be done in an hour. Because the tool walks you through the process, so you can't really miss anything", referring to how the learnability of Sustainable Minds enhanced its usability. In a similar vein, P3 described his experience with Ecolizer, "I don't think it really took that long. Maybe an hour I think, to get the base functionality." P3 pointed out how the learning process was hastened when the interface and icons were similar to familiar tools. For example, the hierarchical model structure of parts, sub-assemblies, and assemblies in Sustainable Minds and Ecolizer resembled what he was accustomed to on CAD tools, making them more intuitive.

Another challenge is picking impact assessment methodologies, which vary by the impacts measured, their weights, and normalization. This decision was confusing to new users who were unaware of the inherent trade-offs, and it is further complicated by lack of consistency among different tools. GaBi and SimaPro offer various choices such as ReCiPe midpoint, endpoint, and single scores (Goedkoop et al., 2008) and the TRACI score (Bare, 2011). Sustainable Minds only computes TRACI, Ecolizer only computes ReCiPe single score, and EarthSmart offers the ReCiPe scores plus their own methodology. Overall, novice users are least accommodated by SimaPro and GaBi. P1 said, "I feel like it probably took me eight hours to get to a point where I could begin to put a model together", referring to SimaPro. He added, "Even then, I am definitely still on the learning curve. I have not got a full understanding of everything." $\mathrm{P} 1$ also used GaBi and had to spend a "week-and-a-half" learning how to use it despite prior experience with SimaPro. Participants expressed feeling less confident about the results and hesitant to adopt LCA in their practice, when daunted by tool complexity.

\subsubsection{Breadth and depth of databases}

Users rely on compiled life cycle inventory (LCI) databases when building an LCA model. Some tools (e.g., $\mathrm{GaBi}$, SimaPro) offer a range of databases, helping users build more robust models. GaBi claims to have the "largest LCI data industry coverage worldwide", offering several industry-specific data modules. We observed that such breadth and depth of available databases is a key factor influencing tool choice. As P1 put it: "The only reason we started using GaBi was because of their extensive electronics database." This ability to utilize comprehensive data may even compel somewhat reluctant selection of a less usable tool, which GaBi was for P1: "It's easiest to use [GaBi's] databases in their software. If we could easily use their databases elsewhere, then I probably would have done that."

A user's industry also affects their database needs. For example, our participants develop consumer electronics products, and they were dissatisfied when tools failed to provide in-depth and up-to-date electronics data. P1 noted, "On SimaPro, a printed circuit board assembly entries have much broader averages. They don't let you dig into the details as much. The electronics make up over 90 percent of the impact of our products, and we want to have a detailed understanding of what is causing that." P2 also considered the ecoinvent 2.2 (2010) database on Sustainable Minds to be "obsolete".

\subsubsection{Reliability of results}

Reliability of results generated was found to be another determining factor in the selection of an LCA tool. This is largely affected by the following different kinds of uncertainty creeping into results.

First, a tool's complexity coupled with a user's lack of background in LCA concepts can produce inefficiency and erroneous outcomes. Participants described often feeling "uncertain and confused" which led to errors during modelmaking, followed by a painful recovery process of trial-and-error until they learned workarounds. P1 described the frustration of such experiences in GaBi, noting, "I did not know how to do what I wanted to do." P4 expressed a similar link between uncertainty and capability in using EarthSmart: "It might be my inability to use this in an efficient way. I find that I'm mostly working around problems rather than figuring them out maybe in a better way." 
Second, there is inherent uncertainty baked into the inventory databases. Problematically, this hidden uncertainty goes unnoticed, especially by novice users, since tools do not account for it when reporting results. P3 expressed the importance of transparency with database uncertainties because they could impact subsequent decision-making: "I would like it [the analysis] to communicate clearly that there is uncertainty because I am trying to make decisions based on this."

Finally, performing an LCA early-on means there will be uncertainty in the information a user inputs. That is, the exact quantities, and choices of materials, processes, and end-of-life pathways may not have yet been determined. Users therefore make estimates and guesses contributing to uncertainty. Unfortunately, none of the tools evaluated allow users to account for the uncertainty in input data when calculating and visualizing impacts.

\subsubsection{Effectiveness of visualizations - interpretation and collaboration}

Interviews highlighted how participants desire visualizations that support both interpretation and communication of insights, which they can then translate to design decisions. Ecolizer uses a pie chart (Fig 1.D) to represent impacts by life cycle stage. P3 noted that "it was harder to see" the small sections of the pie and that such representations were "not useful when making comparisons."

On the other hand, P2 explained that Sustainable Minds aided interpretation by making it easy to recognize the primary contributors to environmental impact: "It shows that the important area for us to look at here is manufacturing." She then looked at the part/sub-assembly level stacked bar graph (Fig 1.B) to identify what the exact sources of the impact were. P2 appreciated that the tool allows for comparison across different concepts from the same project.

Besides bar charts, SimaPro represents impacts with a unique Sankey diagram (Fig 1.A), which was received favorably by P1 (e.g., "It was really useful to communicate the sources of the biggest impacts. [I] simply grabbed a screenshot of the chart to share with colleagues.") SimaPro uses these Sankey Diagrams to illustrate the source, flow, and magnitude of environmental impacts, making it effective for comparisons within the lifecycle of a given product concept to identify sustainability hotspots, although it does not support comparisons across different concepts.
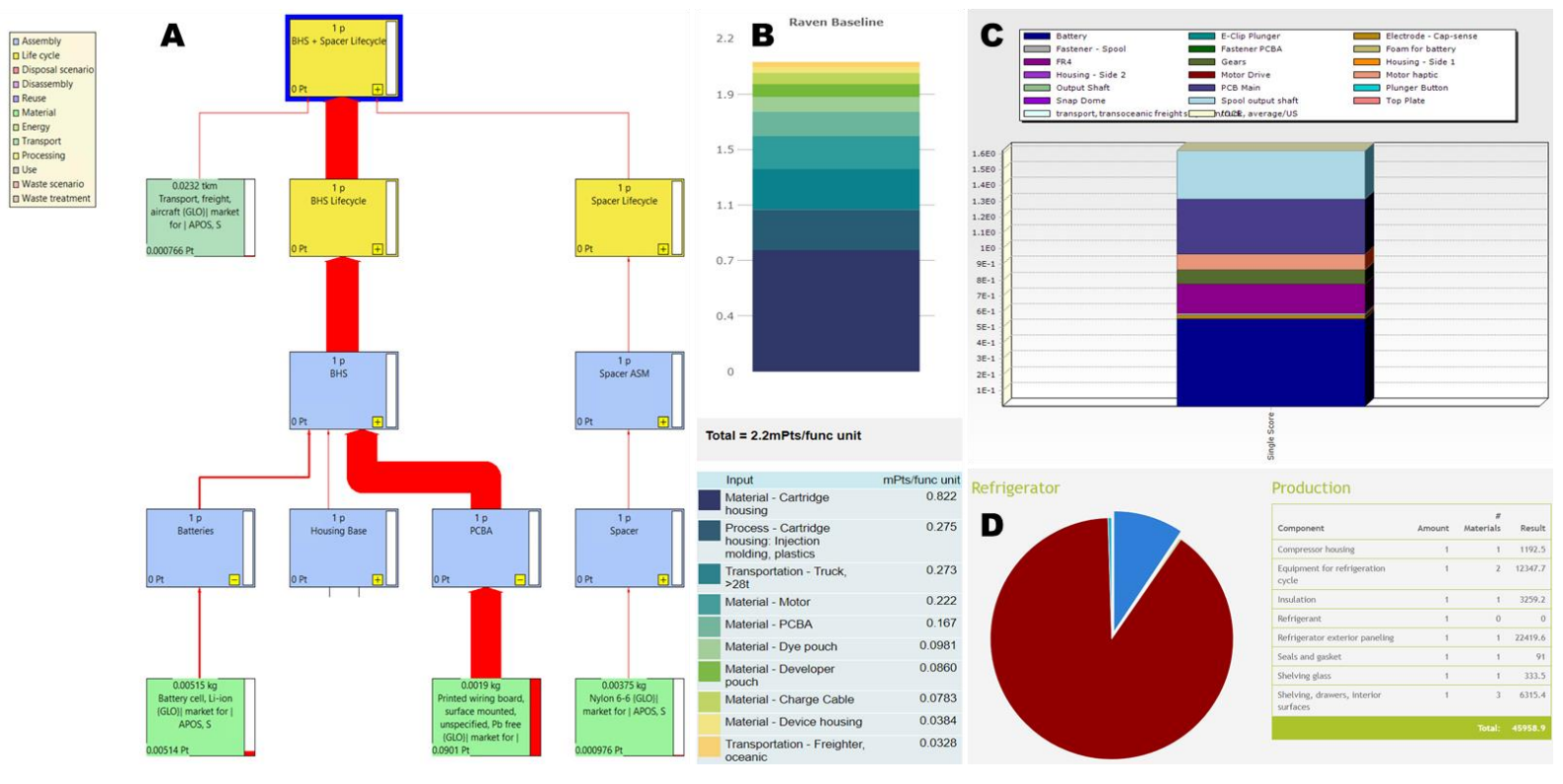

Figure 1. Screenshots of visualizations from tools evaluated: A) SimaPro, B) Sustainable Minds, C) EarthSmart, D) Ecolizer

\subsubsection{Standalone use capabilities}

Participants noted that LCA tools did not fully support their end-to-end needs, leading them to use other tools to fill in the gaps. In particular, all participants preferred to export the data to Excel to generate their own custom visualizations when communicating results. P3 noted that he would review the tool-generated graphs with internal colleagues but transfer to Excel to create graphs for clients. P1 similarly explained how he would "polish the graph on Excel" when reporting to clients. Participants agreed on the value for LCA tools to offer additional customization capabilities. 


\subsection{Rating and ranking of tools}

\subsubsection{Criteria for evaluation}

After interviews, participants rated the LCA tools they used, given the following criteria. These factors reflect the themes extracted from interviews and were further refined based on the usability literature.

- Learnability relates to the duration and complexity of the initial learning process associated with learning to effectively use a particular tool. (Grossman et al., 2009)

- Ease of use refers to a tool's usability, which entails the fulfillment of effectiveness, efficiency, and satisfaction during interactions with it. (Bevan et al., 2015)

- $\quad$ Breadth and depth of databases relates to the choice of inventory databases, including access to specialized sources, in the Life Cycle Inventory (LCI) phase of the model-making process.

- Reliability of results is affected by various forms of uncertainty stemming from: a user's lack of experience, inaccuracies in the database, and a lack of precision in input data.

- Effectiveness of results-visualization encompasses both the aesthetics of the visualizations generated as well as their ability to aid sensemaking and communication. (Wilke, 2019)

- $\quad$ Cost reflects the expenses of purchasing tool licenses and access to inventory databases.

Learnability and ease of use were weighted highest because time was the biggest barrier to integrating LCA into the firm's PD workflow. Having more flexibility and choice in databases was similarly critical to their choice of tool. Effectiveness of visualizations was weighted second highest. Participants worked around the reliability of results by performing LCAs on multiple tools to validate results. Cost was not seen as a significant constraint for this firm.

\subsubsection{Evaluation scores}

Using the above metrics on a scale of 1-5, participants rated their experiences with LCA tools. Table 2 provides average ratings. This paper's insights and design recommendations are primarily based on the qualitative interview data, with the ratings summarizing the aggregate attitudes towards each tool.

Table 2. Participants' rating of LCA tools on five criteria using a 1-5 scale, weighted according to the impact we found each metric had on user experiences and LCA outcomes

\begin{tabular}{|l|l|c|c|c|c|c|c|c|}
\hline \multirow{2}{*}{ Tool } & Factor & Learnability & $\begin{array}{c}\text { Ease of } \\
\text { use }\end{array}$ & $\begin{array}{c}\text { Breadth \& } \\
\text { depth of } \\
\text { database }\end{array}$ & $\begin{array}{c}\text { Reliability } \\
\text { of results }\end{array}$ & $\begin{array}{c}\text { Effectiveness } \\
\text { of results- } \\
\text { visualization }\end{array}$ & Cost & \multirow{2}{*}{ Total } \\
\hline Sustainable Minds & 4 & 4 & 2 & 3 & 3 & 4 & 3.3 \\
\hline Ecolizer BE & 3 & 4 & 3 & 3 & 2 & 5 & 3.2 \\
\hline SimaPro & 1 & 1 & 5 & 5 & 3 & 1 & 2.5 \\
\hline GaBi & 1 & 1 & 5 & 5 & 3 & 1 & 2.5 \\
\hline EarthSmart & 2 & 1 & 4 & 4 & 1 & 3 & 2.25 \\
\hline
\end{tabular}

These ratings closely reflect the qualitative insights obtained from the interviews. Sustainable Minds scored highest overall, owing to its short learning curve, relatively intuitive interface, and low cost. Ecolizer came a close second, falling behind on results-visualization. P3 alluded to how the tool only offered pie-chart representations, which were not conducive to making comparisons, and the tool's limited customization capabilities. Being free, Ecolizer scored best on cost.

SimaPro and $\mathrm{GaBi}$ scored highest on database offerings and result reliability, which is consistent with their status as industry-standard tools used by experts to generate sustainability reports. Both provide a wide range of database and impact assessment methodology choices. However, both tools were found to be complex, unintuitive, difficult to learn, and expensive, leading to low scores on those factors. Finally, EarthSmart offers more features than Sustainable Minds and Ecolizer, but the additional complexity hurts its learnability and ease of use. 


\section{DISCUSSION}

\subsection{Design implications}

The qualitative insights from our interviews with participants and their subsequent ratings of LCA tools illuminate shortcomings of existing tools to cater to the needs of an early-stage product development (PD) context and novice LCA users. Aiming to address these limitations and offer directions for the design of more effective LCA tools going forward, we ask the following:

- How might we $(H M W)$ manage the ways time constrains the application of LCA? Our users face intense time pressure in their PD practice. We recommend improving a tool's upfront learnability and ease of use so it can be applied efficiently and effectively from the start.

- HMW make LCA results more reliable? We found that trust in results was impeded by uncertainties in input data, the databases themselves, and users' confidence in model-making.

- HMW facilitate iterative refinement of models? We learnt that iterative refinement of models could be supported by easing error recovery and enabling version control.

- $\quad H M W$ support interpretation and communication of LCA results? Successfully integrating LCA into PD hinges on enabling sensemaking and communication of LCA results, which users can then collaboratively translate into tangible design decisions. We recommend that tools should enable greater flexibility and customizability when visualizing impacts.

Table 3 presents these HMW questions, followed by the identified shortcomings that motivated them, and our high-level design recommendations to address these issues. While not exhaustive, they can guide future research to better tailor LCA tools to product designers.

Table 3. HMW questions and design recommendations for future LCA tools

\begin{tabular}{|c|c|c|}
\hline HMW questions & Shortcomings & Design recommendations \\
\hline \multirow{6}{*}{$\begin{array}{l}\text { HMW manage the ways } \\
\text { time constrains the } \\
\text { application of LCA? }\end{array}$} & \multirow{3}{*}{ Learnability } & $\begin{array}{l}\text { Improve familiarity through resemblance with } \\
\text { commonly used tools like Excel and CAD }\end{array}$ \\
\hline & & Reduce tool complexity \\
\hline & & $\begin{array}{l}\text { Include walkthrough tutorials, tool-tips, } \\
\text { examples }\end{array}$ \\
\hline & \multirow{3}{*}{ Ease of use } & Limit number of clicks required \\
\hline & & $\begin{array}{l}\text { Improve intuitiveness of the process (e.g., by } \\
\text { offering a progress bar, hints, etc.) }\end{array}$ \\
\hline & & Design the interface with UX principles in mind \\
\hline \multirow{6}{*}{$\begin{array}{l}\text { HMW make LCA results } \\
\text { more reliable? }\end{array}$} & \multirow{4}{*}{$\begin{array}{l}\text { Input data } \\
\text { uncertainty }\end{array}$} & $\begin{array}{l}\text { Allow users to enter uncertainty values, for the } \\
\text { overall model and for individual entries } \\
\end{array}$ \\
\hline & & $\begin{array}{l}\text { Account for the uncertainty in the results } \\
\text { visualization }\end{array}$ \\
\hline & & $\begin{array}{l}\text { Highlight overlapping error bars that may } \\
\text { prevent users from confidently identifying } \\
\text { hotspots }\end{array}$ \\
\hline & & $\begin{array}{l}\text { Allow users to track decreases in uncertainty } \\
\text { across versions as the product concept matures }\end{array}$ \\
\hline & $\begin{array}{l}\text { Database } \\
\text { uncertainty }\end{array}$ & Account for the uncertainty in the database \\
\hline & Lack of confidence & Reduce tool complexity and enhance usability \\
\hline \multirow{3}{*}{$\begin{array}{l}\text { HMW facilitate iterative } \\
\text { refinement of models? }\end{array}$} & \multirow{3}{*}{ Error recovery } & Limit errors by improving intuitiveness \\
\hline & & $\begin{array}{l}\text { Flag inputs for review if they seem off compared } \\
\text { to the rest of the model }\end{array}$ \\
\hline & & $\begin{array}{l}\text { Allow users to trace an anomalous data point in } \\
\text { the visualization back to its source model- } \\
\text { making }\end{array}$ \\
\hline
\end{tabular}




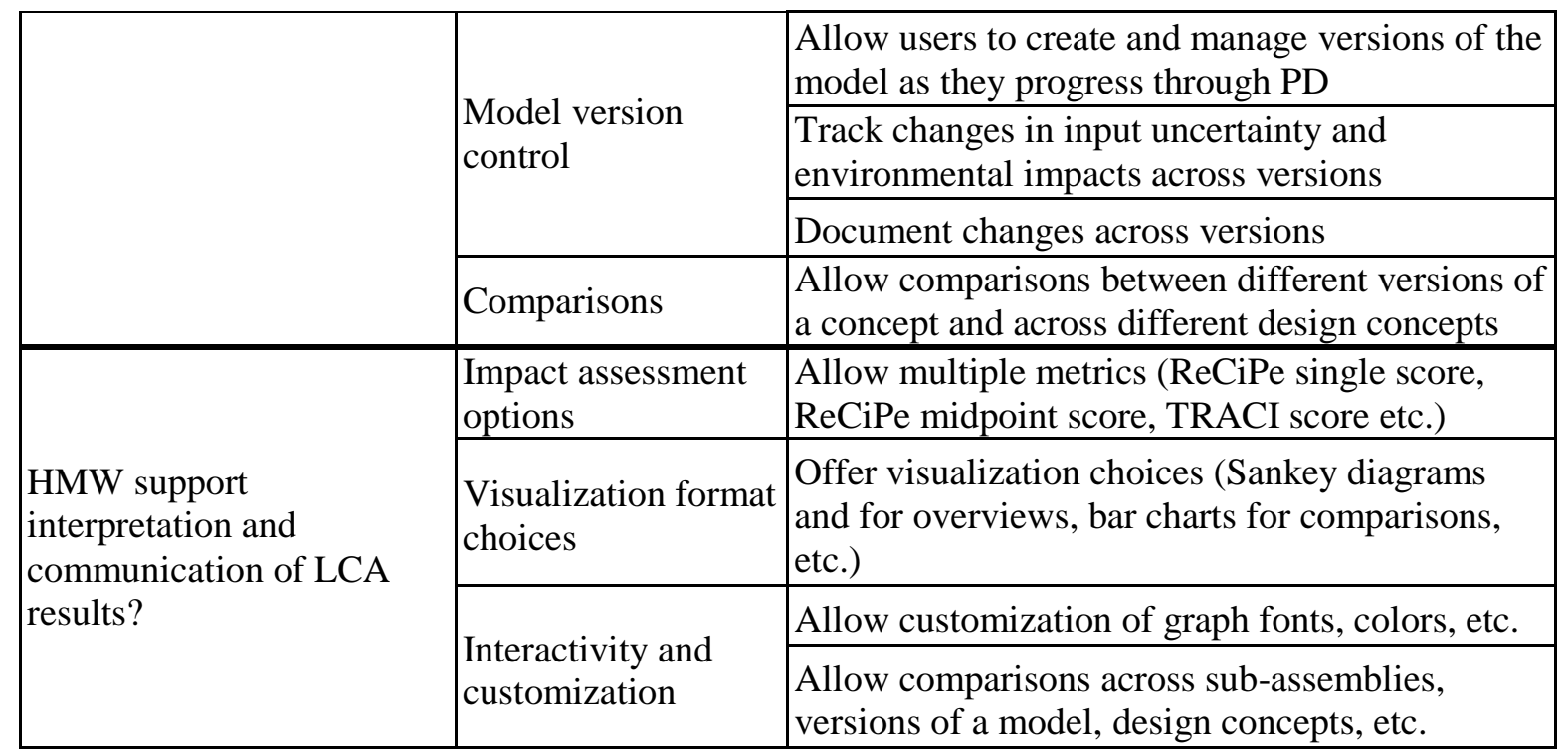

\subsection{Limitations and future work}

This study was conducted at a PD consultancy to help integrate sustainability considerations into their practices. Our interviews were limited to a small group of participants. The first authors' embedding into the company promoted deep understanding of practices and rich feedback; however, only one interview was conducted per tool. We are currently recruiting an expanded participant base to include practitioners from other industries. To solidify our tool ratings, we are working to distribute surveys to a broader group of target users via LinkedIn groups and other professional communities, asking participants to rate the tools on our aforementioned metrics. Finally, our design recommendations require implementation and testing to confirm their utility. We are currently developing a novel LCA tool that addresses the gaps identified in this paper and applies the guidelines proposed. Essential to the process are human-centered methods, including ongoing engagement with target users to gather feedback on iteratively refined prototypes, and rigorous user testing and eventual deployments to evaluate the tool in real-world contexts.

\section{CONCLUSION}

This paper investigated the effectiveness of existing LCA software in catering to the needs of earlystage PD practice. LCA as a methodology allows for quantifying environmental impacts across the overall life cycle of a product, making it a powerful approach for data-driven sustainable design. Our study was conducted in the context of an engineering consultancy firm seeking to systematically integrate sustainability considerations into their PD workflow. Specifically, we performed in-depth semi-structured interviews with users about their experience with several prominent LCA tools, and identified high-level themes related to the tools' perceived ease of use, learnability, breadth and depth of databases, reliability of results, effectiveness of visualizations, and cost. Participants also rated the tools based on these factors, which helped us quantify and rank different tools in terms of their perceived ability to support early-stage design processes and users who are new to LCA.

Unfortunately, we found that all of the tools failed on one or more of these criteria, forcing the firm to purchase licenses to multiple tools, to compensate for the assorted shortcomings. We saw that not only does this inhibit effective and efficient application of LCA, but that the associated expenses pose a financial barrier to employing LCA thereby impeding the successful adoption of this highly valuable method. Given the growing imperative to incorporate sustainability considerations into PD, particularly at early stages, the insights and design recommendations contributed by our study are salient and timely and offer directions for developing novel LCA tools tailored to the PD context. We encourage others to build on the findings of this research, to similarly work towards making LCA and sustainable design more accessible to product designers.

\section{REFERENCES}

Antelmi, P. D. C. and Sousa, S. R. (2011) "Life cycle assessment (LCA): Discussion on full-scale and simplified assessments to support the product development process," in 3rd International Workshop on Advances in Cleaner Production. 
Agustí-Juan, I. and Habert, G. (2017), “Environmental design guidelines for digital fabrication”, Journal of Cleaner Production.

Bare, J. (2011), "TRACI 2.0: the tool for the reduction and assessment of chemical and other environmental impacts 2.0", Clean Technologies and Environmental Policy.

Baumann, H., Boons, F. and Bragd, A. (2002), "Mapping the green product development field: engineering, policy and business perspectives", Journal of Cleaner Production.

Bevan, N., Carter, J. and Harker, S. (2015), "ISO 9241-11 Revised: What Have We Learnt About Usability Since 1998?", Human-Computer Interaction: Design and Evaluation.

Bhander, G.S., Hauschild, M. and McAloone, T. (2003), "Implementing life cycle assessment in product development”, Environmental Progress, Vol. 22 No. 4, pp. 255-267.

Bocken, N.M.P., Allwood, J.M., Willey, A.R. and King, J.M.H. (2012), "Development of a tool for rapidly assessing the implementation difficulty and emissions benefits of innovations", Technovation.

Braun, V. and Clarke, V. (2006), "Using thematic analysis in psychology", Qualitative Research in Psychology.

Casamayor, J.L. and Su, D. (2012), "Integration of detailed/screening LCA software-based tools into design processes", Design for Innovative Value Towards a Sustainable Society.

Chang, D., Lee, C.K.M. and Chen, C.-H. (2014), "Review of life cycle assessment towards sustainable product development", Journal of Cleaner Production.

Chiu, M.-C. and Chu, C.-H. (2012), "Review of sustainable product design from life cycle perspectives", International Journal of Precision Engineering and Manufacturing.

Curran, M.A. (2016), Goal and Scope Definition in Life Cycle Assessment, Springer.

Depping, V., Grunow, M., van Middelaar, C. and Dumpler, J. (2017), "Integrating environmental impact assessment into new product development and processing-technology selection: Milk concentrates as substitutes for milk powders", Journal of Cleaner Production.

Devanathan, S., Ramanujan, D., Bernstein, W.Z., Zhao, F. and Ramani, K. (2010), "Integration of Sustainability Into Early Design Through the Function Impact Matrix”, Journal of Mechanical Design.

Gong, X., Nie, Z., Wang, Z. and Zuo, T. (2006), "Research and development of Chinese LCA database and LCA software", Rare Metals.

Grossman, T., Fitzmaurice, G. and Attar, R. (2009), “A survey of software learnability”, Proceedings of the 27th International Conference on Human Factors in Computing Systems - CHI 09

Herrmann, I.T. and Moltesen, A. (2015), "Does it matter which Life Cycle Assessment (LCA) tool you choose? - a comparative assessment of SimaPro and GaBi”, Journal of Cleaner Production.

Januschkowetz, A. and Hendrickson, C.T. (2001), "Product and process life cycle inventories using SAP R/3", Proceedings of the 2001 IEEE International Symposium on Electronics and the Environment.

Johansson, G. (2002), "Success factors for integration of ecodesign in product development", Environmental Management and Health.

Khurana, A. and Rosenthal, S.R. (1998), “Towards Holistic 'Front Ends' In New Product Development”, Journal of Product Innovation Management.

Kuo, T.-C., Smith, S., Smith, G.C. and Huang, S.H. (2016), “A predictive product attribute driven eco-design process using depth-first search", Journal of Cleaner Production.

Lacasa, E., Santolaya, J.L. and Biedermann, A. (2016), “Obtaining sustainable production from the product design analysis", Journal of Cleaner Production.

Lockrey, S. (2015), “A review of life cycle based ecological marketing strategy for new product development in the organizational environment", Journal of Cleaner Production.

Millet, D., Bistagnino, L., Lanzavecchia, C., Camous, R. and Poldma, T. (2007), "Does the potential of the use of LCA match the design team needs?", Journal of Cleaner Production www.nngroup.com/articles/usability-101-introduction-to-usability/.

Goedkoop, M., Heijungs, R., Huijbregts, M., Schryver, A., Struijs, J. and van Zelm, R., 2008. Recipe. [online] Available at: <https://www.researchgate.net/publication/230770853_Recipe_2008>

Rattanatum, T., Frauzem, R., Malakul, P. and Gani, R. (2018), "LCSoft as a Tool for LCA: New LCIA Methodologies and Interpretation", Computer Aided Chemical Engineering.

Russo, D., Rizzi, C. and Montelisciani, G. (2014), "Inventive guidelines for a TRIZ-based eco-design matrix", Journal of Cleaner Production.

Suppipat, S., Teachavorasinskun, K. and Hu, A. H. (2021) "Challenges of applying simplified LCA tools in sustainable design pedagogy,” Sustainability, 13(4), p. 2406.

Ulrich and Eppinger, S. (2020). Product Design and Development, 7th Ed., McGraw-Hill Higher Education.

Wilke, C.O. (2019), Fundamentals of Data Visualization: A Primer on Making Informative and Compelling Figures, O’Reilly Media. 